\title{
DOWNSCALING METHODS OF FLOW VARIABLES FOR SCALE INVARIANT ROUTING MODEL
}

\author{
Nawa Raj PRADHAN 1 , Yasuto TACHIKAWA ${ }^{2}$ and Kaoru TAKARA ${ }^{3}$ \\ ${ }^{1}$ Student member of JSCE, Graduate Student, Dept. of Civil Eng., Kyoto University, \\ (Yoshida Honmachi, Sakyo-ku, Kyoto, 606-8501, Japan) \\ ${ }^{2}$ Member of JSCE, Dr. Eng., Associate Professor, DPRI, Kyoto University, (Gokasho, Uji, 611-0011, Japan) \\ ${ }^{3}$ Fellow of JSCE, Dr. Eng., Professor, DPRI, Kyoto University, (Gokasho, Uji, 611-0011, Japan)
}

\begin{abstract}
It is found that basin hydrological response and model effective parameter identification in relations with the drainage basin dominating geomorphological parameters is directly influenced by the scale of DEM resolution. Thus a scale independent relationship in flood routing models is necessary for consistency in rainfall runoff translation at a scale of interest. To overcome this problem downscaling methods of dominating geomorphometric parameters are used to obtain the scale invariant distribution function of cross-section, depth, discharge and wave celerity from different DEM resolutions. The downscaling methods of the flow variables is then coupled with the Muskingum-Cunge routing method to develop a scale invariant routing model.
\end{abstract}

Key Words: geomorphological parameters, flow variables, routing model, downscale

\section{INTRODUCTION}

Hydrological geomorphology is literally the interface between hydrology, the science of water and geomorphology, the study of landforms and their causative processes. It can be argued that the major challenge facing geomorphologists is in understanding scale dependencies of form and process. Such an understanding allows observations made at convenient scales to be extrapolated to other less well observed scales.

Beyond a single hillside, a river basin can be viewed as a channel-network-hills system. The hydrologic cycle for larger sub-basins involves the spatially integrated behaviors of several hills along a channel network. An understanding of the spatial variability among hillsides and their interactions through a channel network is necessary for this integration. Thus, at this point scale invariance in surface wave models finds an important component of the hydrologic cycle in river-basin hydrology. Although the relative importance of the components in the rainfall-runoff transformation process depends both on its working scale and on the geographical, climatic and environmental conditions of the site under consideration, the relative importance of routing phenomenon in surface flow hydrology cannot be ignored for a complete process model that offers a detailed description of the rainfall-runoff transformation.

Flow routing in open channels entails wave dispersion, wave attenuation or amplification and wave retardation or acceleration. These wave characteristics constitute the hydraulics of flow routing or propagation and are greatly affected by the geometric characteristics of channels. The flow variables whose propagation characteristics are of interest are discharge, velocity, depth, cross-section, volume and duration.

In this study we focus on the development of scale independent routing parameters. Pradhan et al. 1) developed a scale invariant model for the topographic index of TOPMODEL for the effective translation of the scale dependence relations of topography into effective hydrological model, TOPMODEL ${ }^{2}$. Here, we use the method to down scale the topographic index distribution in producing scale independent runoff component in TOPMODEL framework ${ }^{3)}$. With the scale independent runoff producing mechanism, the scale dependence of the flow variables and the routing effective parameters are analyzed in the Muskingum 


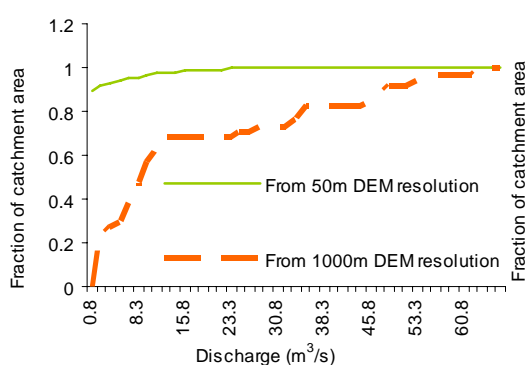

(a)

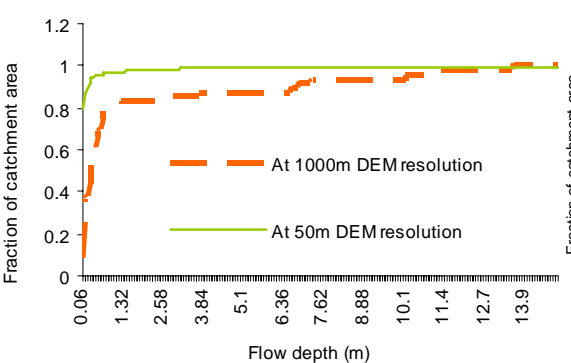

(b)

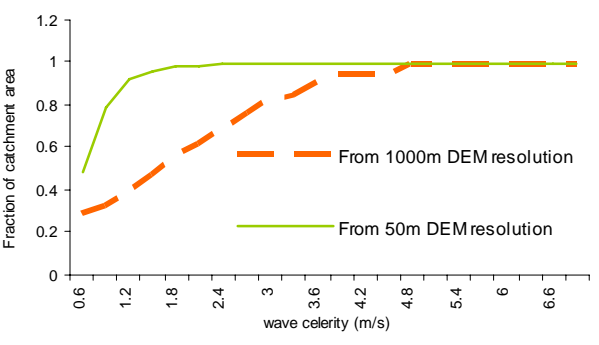

(c)

Fig. 1 Comparison of flow variables distribution from different DEM resolutions in the Kamishiiba catchment $\left(210 \mathrm{~km}^{2}\right)$ at time step 43 hours of the rainfall event. (a) Discharge distribution comparison (b) flow depth distribution comparison and (c) wave celerity distribution comparision.

Cunge routing ${ }^{4}$ ). The downscaling method of the geomorphologic parameters is used to develop the downscaling method of the flow variables. Finally, coupling the downscaling method of the flow variables with the Muskingum-Cunge routing method, a scale independent routing model is developed.

\section{SCALE DEPENDENCE OF MUSKINGUM-CUNGE ROUTING METHOD ON DEM RESOLUTION}

A wave is a variation in flow, such as a change in flow rate or water surface elevation, and the wave celerity is the velocity with which this variation travels along the channel. The kinematic wave celerity, $c_{i}$, can be defined in terms of flow depth by Equation (1).

$c_{i}=\frac{5}{3}\left(\frac{S_{i}^{1 / 2}}{n}\right) y_{i}^{2 / 3}$

where $S_{i}$ is the slope at a point $i$ and $n$ is the Manning's roughness coefficient. $y_{i}$ is the depth of flow and is expressed as;

$$
y_{i}=\left(\frac{n Q_{i}}{S_{i}^{1 / 2} B_{i}}\right)^{3 / 5}
$$

where $Q_{i}$ and $B_{i}$ are the flow rate and channel width respectively at a point $i$.

In a distributed system, routing the river flow is calculated as a function of space and time through the system. Referring to the time-space computational grid, the Muskingum-Cunge routing equation can be written for the discharge $Q_{i+1}^{j+1}$ at $x$ $=(i+1) \Delta x$ and $t=(j+1) \Delta t$ as;

$$
\begin{aligned}
& Q_{i+1}^{j+1}=C_{1} Q_{i}^{j}+C_{2} Q_{i}^{j+1}+C_{3} Q_{i+1}^{j} \\
C_{1}= & \frac{\Delta t+2 X K}{2 K(1-X)+\Delta t} \\
C_{2}= & \frac{\Delta t-2 X K}{2 K(1-X)+\Delta t} \\
C_{3}= & \frac{2 K(1-X)-\Delta t}{2 K(1-X)+\Delta t} \\
K= & \frac{\Delta x}{c}
\end{aligned}
$$

where $K$ is the flood-wave travel time over a reach with length $\Delta x . X$ is a weighting coefficient evaluated as;

$$
X=\frac{1}{2}\left(1-\frac{Q_{i}}{B S c \Delta x}\right)
$$

where $S$ is the channel bed slope and $B$ is the channel width.

In Muskingum-Cunge routing method $Q_{i}$ in Equation (2) and Equation (8) is taken as $Q_{i}^{j+1}$ in Equation (3) where,

$Q_{i}^{j+1}=$ Inflow discharge at time $(j+1)$ in cell $i+$ generated water in cell $i$

Figure 1 (a), (b) and (c) respectively show much difference in the distribution of discharge $Q_{i}$, depth $y_{i}$ and wave celerity $c_{i}$ obtained from $50 \mathrm{~m}$ DEM resolution and from $1000 \mathrm{~m}$ DEM resolution in the Kamishiiba catchment $\left(210 \mathrm{~km}^{2}\right)$ when keeping the same value of Manning's roughness coefficient, 0.025 , identified at $50 \mathrm{~m}$ DEM resolution Muskingum-Cunge routing model. The scale effect analysis in Figure 1 is made at time step 43 hours of 


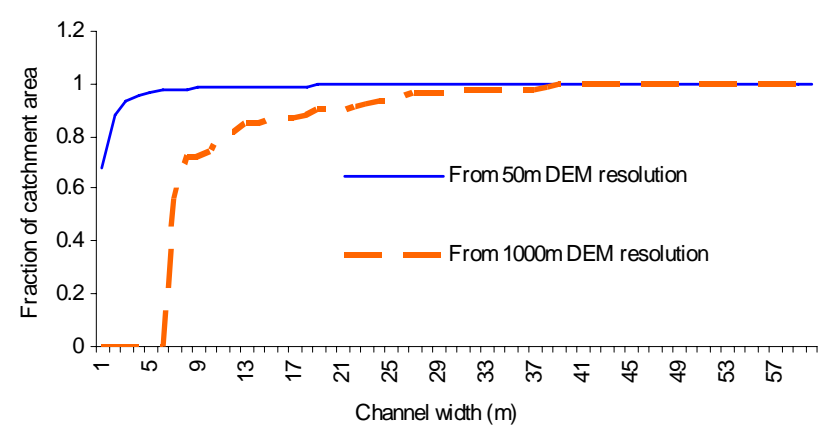

(a)

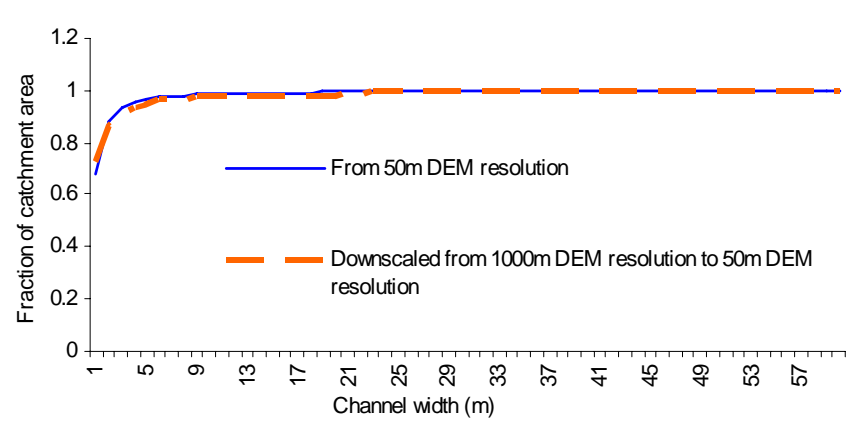

(b)

Fig. 2 Comparison of channel width distribution from different DEM resolutions in the Kamishiiba catchment $\left(210 \mathrm{~km}^{2}\right)$, (a) without downscaling method introduced (b) with downscaling method introduced.

the rainfall event to show how the flow variables are affected by the scale of DEM in the runoff generated time steps. As the flow variables and the effective Manning's roughness coefficient in Equations (1) and (2) are DEM data resolution dependent, the routing parameters $K$ and $X$ in Equations (7) and (8) are also affected by the DEM data resolution.

\section{DERIVING CHANNEL WIDTH INFORMATION AT FINER SCALE}

In hill slope channel routing, one of the difficult task is defining the channel width. The channel width less than the DEM grid resolution used cannot be obtained. Although the channel width is obtained as a function of upslope catchment area or discharge as explained by Leopold and Maddock 5), the width of reaches still cannot be obtained where the finer information of upslope catchment area or discharge taken as independent variable is filtered out by the use of a coarse DEM. Here, channel width is derived as a function of upslope catchment area as given by Equation (10).

$$
B_{i}=a C_{i}^{b}
$$

where $B_{i}$ is the channel width at a location $i$ and $C_{i}$ is the upslope catchment area at that location. $a$ and $b$ are the coefficients. The coefficients $a$ and $b$ are calibrated as 7.0 and 0.4 respectively at $50 \mathrm{~m}$ DEM resolution. Figure 2 (a) shows the comparison of channel width distribution from $50 \mathrm{~m}$ and $1000 \mathrm{~m}$ DEM resolutions in the Kamishiiba catchment (210 $\mathrm{km}^{2}$ ). In Figure 2 (a), it is shown that the percentage of smaller width values is much lesser when using $1000 \mathrm{~m}$ DEM resolution than when using 50m DEM resolution.
Thus scaled upslope catchment area ${ }^{6}$

$$
C_{i, \text { scaled }}=\left(\frac{C_{i}}{N_{s} I_{f}}\right)
$$

is introduced in Equation (10) and downscaled channel width at a location $i, B_{i, \text { scaled }}$ is obtained as;

$$
B_{i, \text { scaled }}=a C_{i, \text { scaled }}^{b}
$$

where $N_{s}$ is the total number of sub-grids within a coarse resolution grid, the suffix $i$ is a location in a catchment; $C_{i}$ is the upslope catchment area of the coarse resolution DEM, $C_{i, \text { scaled }}$ is the scaled upslope catchment area at a point $i$ and $I_{f}$ is introduced as influence factor ${ }^{6}$..$I_{f}$ is defined as;

$$
I_{f}=e^{\left\{\frac{\left(1-N_{i}\right) H}{N_{o}}\right\}}
$$

where, $N_{i}$ is the number of the coarse resolution grids contained in the upslope contributing area at a location $i$ in the catchment; $N_{o}$ is the number of the coarse resolution grids contained in the upslope catchment area at the outlet of the catchment and $H$ is the harmony factor ${ }^{6)}$ defined as;

$$
H=\frac{N_{o}}{N_{o}-1} \ln N_{s}
$$

In Figure 2 (b) it is shown that the distribution of downscaled channel width from 1000 m DEM resolution to $50 \mathrm{~m}$ DEM resolution and that from $50 \mathrm{~m}$ DEM resolution has matched. Thus, by using Equation (11) the loss portion of channel width at finer scale, 50m DEM resolution, is successfully obtained by using only a coarse resolution DEM, $1000 \mathrm{~m}$ DEM resolution. 


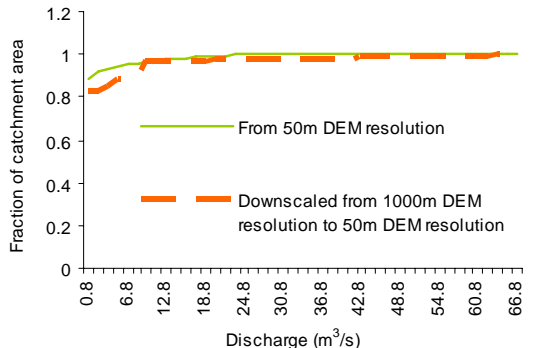

(a)

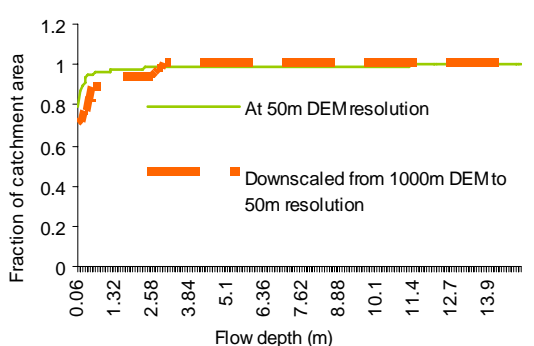

(b)

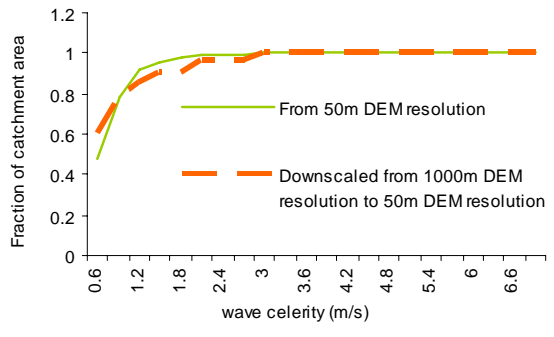

(c)

Fig. 3 Comparison of flow variables distribution from different DEM resolutions with the downscaling methods of the flow variables in the Kamishiiba catchment $\left(210 \mathrm{~km}^{2}\right)$ at time step 43 hours of the rainfall event. (a) Discharge distribution comparison (b) flow depth distribution comparison and (c) wave celerity distribution comparison.

\section{DERIVING DISCHARGE INFORMATION AT FINER SCALE}

As the drainage area increases downstream, the actual discharge in downstream reaches also increases. Flow rate $Q_{i}$ is a function of upslope contributing area ${ }^{7)}$. From Figure 1 (a) it is seen that the percentage of smaller discharge values is much lesser when using $1000 \mathrm{~m}$ DEM resolution than when using 50m DEM resolution.

In fact the smallest discharge value derived from a DEM resolution is the discharge produced by a single grid of the DEM at that resolution. Thus discharge values smaller than that produced by the grid size smaller than a grid size in the DEM is completely lost as the larger sampling dimensions of the grids act as filter. But as finer resolution DEM is used, the smaller discharge values - that is the discharge values produced by finer grid resolution is achieved. Figure 1 (a) also shows that in a catchment as the discharge gets bigger and bigger at the downstream points, the discharge values given by coarse and fine resolution DEM at the points downstream becomes closer and closer. This scale phenomenon in discharge with DEM resolution is just similar to the scale phenomenon for upslope contributing area ${ }^{6)}$. For this reason similar to Equation (11), number of sub grids, $N_{s}$, and influence factor $I_{f}$ is introduced as the downscaling factors for discharge as shown in Equation (15).

$$
Q_{i, \text { scaled }}=\left(\frac{Q_{i}}{N_{s} e^{\left\{\frac{\left(1-N_{i}\right) H}{N_{o}}\right\}}}\right)
$$

In contrast to Figure 1(a), Figure 3 (a) shows that the distribution of discharge from $1000 \mathrm{~m}$ DEM resolution to $50 \mathrm{~m}$ DEM resolution and that from $50 \mathrm{~m}$ DEM resolution has matched.

\section{DERIVING FLOW DEPTH INFORMATION AT FINER SCALE}

The underestimation of slopes when using the coarse resolution DEMs can seriously affect the accuracy of hydrologic and geomorphological models. Pradhan et al. ${ }^{1)}$ developed a method to downscale the steepest slope by fractal method which is defined as;

$\theta_{i, \text { scaled }}=\alpha_{i, \text { steepest }} d_{i, \text { scaled }}^{(1-D)}$

where $\theta_{i, \text { scaled }}$ is the scaled steepest slope; $\alpha_{i, s t e e p e s t}$ is a coefficient derived from the steepest slope; $d_{i, s c a l e d}$ is the scaled slope distance and $D$ is the fractal dimension (Refer Pradhan et al., ${ }^{1)}$ for details).

Substituting $Q_{i}, B_{i}$ and $S_{i}$ in Equation (2) by $B_{i, \text { scaled }}$ from Equation (12), by $Q_{i, \text { scaled }}$ from Equations (15) and by $\theta_{i, s c a l e d}$ from Equation (16) respectively, the method to downscale the flow depth, $y_{i, \text { scaled }}$ is developed as;

$$
y_{i, \text { scaled }}=\left(\frac{n Q_{i, \text { scaled }}}{\theta_{i, \text { scaled }}^{1 / 2} B_{i, \text { scaled }}}\right)^{3 / 5}
$$

In contrast to Figure 1 (b), in Figure 3 (b), it is shown that the distribution of downscaled flow depth from $1000 \mathrm{~m}$ DEM resolution to 50m DEM resolution and that from $50 \mathrm{~m}$ DEM resolution (Manning's roughness coefficient $n$ used is identified at 50m DEM resolution) has matched. Thus, by using Equation (17) the over estimation of depth given by $1000 \mathrm{~m}$ DEM resolution shown by Figure 1 (b) is successfully reduced in Figure 3 (b).

\section{DEVELOPMENT OF A SCALE INVARIANT MUSKINGUM-CUNGE ROUTING METHOD}

The propagation speed or celerity of a flood wave is one of the main properties of the flood-wave propagation and is related directly to the wave deformation and attenuation. Hence an investigation into scale effect in celerity is essential for deriving the scale invariance of flood-wave propagation. $K$ and $X$ in Equation (7) and Equation (8) governs the influence of routing in surface flow 


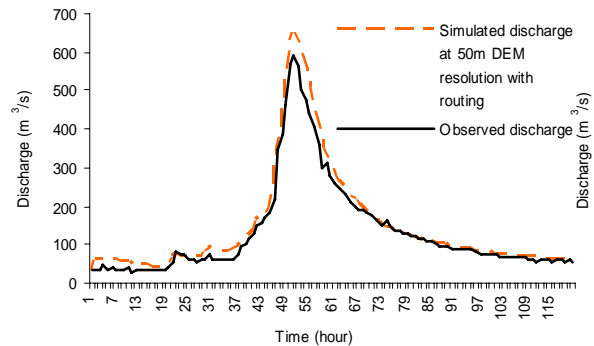

(a)

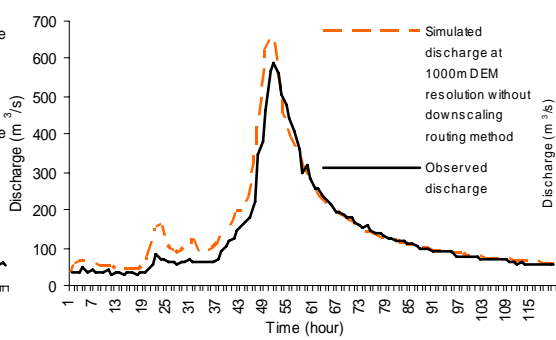

(b)

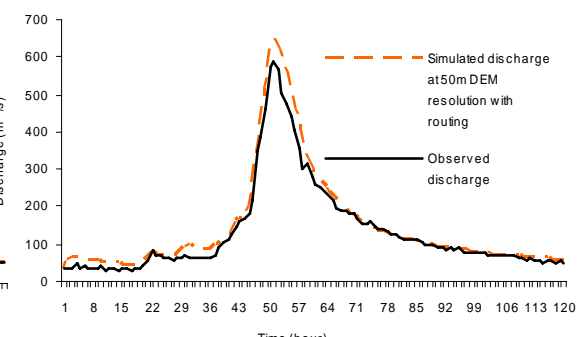

(c)

Fig. 4 Analysis of Muskingum-Cunge routing effect in the Kamishiiba catchment $\left(210 \mathrm{~km}^{2}\right)$. (a) simulation result at 50m DEM resolution where the Manning's roughness coefficient is calibrated; (b) simulation result at 1000m DEM resolution without downscaling the Muskingum-Cunge routing method; (c) simulation result at 1000m DEM resolution with downscaling the Muskingum-Cunge routing method. In all the case, the effective parametric value of Manning's roughness coefficient, $n$, used is identified at 50m DEM resolution and scale independent runoff production mechanism is applied.

hydrologic response in Muskingum-Cunge routing method. The flood wave travel time is derived from wave celerity. The weighting coefficient $X$ in Equation (8) is also dependent on wave celerity. Thus wave celerity is a governing factor in Muskingum-Cunge routing method.

Substituting $y_{i}$ and $S_{i}$ in Equation (1) by $\theta_{i, \text { scaled }}$ from Equation (16) and $y_{i, \text { scaled }}$ from Equation (17), the scaled wave celerity $c_{i, \text { scaled }}$ is developed as;

$$
c_{i, \text { scaled }}=\frac{5}{3}\left(\frac{\theta_{i, \text { scaled }}^{1 / 2}}{n}\right) y_{i, \text { scaled }} 2 / 3
$$

In contrast to Figure 1 (c), in Figure 3 (c), it is shown that the distribution of downscaled celerity from $1000 \mathrm{~m}$ DEM resolution to $50 \mathrm{~m}$ DEM resolution, by using Equation (18), and that from $50 \mathrm{~m}$ DEM resolution (same Manning's roughness coefficient $n$ is used that is identified at $50 \mathrm{~m}$ DEM resolution) has matched.

Thus, by using Equation (18) the over estimation of celerity given by $1000 \mathrm{~m}$ DEM resolution is successfully reduced.

Substituting $c$ in Equation (7) by $c_{i, s c a l e d}$ from Equation (18) the downscaling method of $K$ is defined as;

$$
K_{i, \text { scaled }}=\frac{\Delta x}{c_{i, \text { scaled }}}
$$

Substituting $c$ in Equation (8) by $c_{i, \text { scaled }}$ from Equation (18); $B$ in Equation (8) by $B_{i, \text { scaled }}$ from Equation (12); $S$ in Equation (8) by $\theta_{i, \text { scaled }}$ from Equation (16) and $Q_{i}$ in Equation (8) by $Q_{i, \text { scaled }}$ from Equation (15), the downscaling method of $X$ is defined as;

$$
X_{i, \text { scaled }}=\frac{1}{2}\left(1-\frac{Q_{i, \text { scaled }}}{B_{i, \text { scaled }} \theta_{i, \text { scaled }} c_{i, \text { scaled }} \Delta x}\right)
$$

Equations (19) and (20) are introduced in Muskingum-Cunge routing method to develop Scale Invariant Muskingum-Cunge routing method.

\section{RESULTS AND DISCUSSION}

Figure 4 (a) shows the simulated hydrograph at $50 \mathrm{~m}$ DEM resolution with Nash efficiency of $95 \%$ and the calibrated $n$ value is 0.025 . In addressing the problem of what to route before deciding how to route ${ }^{8)}$, development of a scale independent runoff producing mechanism is important. After obtaining the scale independent runoff production mechanism through the downscaling method of topographic index distribution in TOPMODEL framework ${ }^{1), 3)}$, the Muskingum-Cunge routing method with the same effective value of the Manning's roughness coefficient $n$ identified at $50 \mathrm{~m}$ DEM resolution is applied to $1000 \mathrm{~m}$ DEM resolution, refer Figure 4 (b). Even in a small sized catchment, the Kamishiiba catchment $\left(210 \mathrm{~km}^{2}\right)$, the routing model at $1000 \mathrm{~m}$ DEM resolution shown by Figure 4 (b) is not as effective as that at $50 \mathrm{~m}$ DEM resolution, shown by Figure 4 (a), when applying the same effective parametric value of $n$. Figure 4 (b) still shows the sharp peaks and the hydrograph response is still seen quicker than the actual catchment discharge response. This scale effect in the routed hydrograph could be more significant if the catchment size increases.

The lack in reduction of peaks and routing delays in the simulated hydrograph originates from reduced travel distance of the flood wave when the coarse resolution DEM is used. Even after obtaining the scale invariance in runoff generation mechanism, the saturated area in coarser DEM resolution is more concentrated closer to the outlet whereas in finer resolution DEM, the saturated area extends further upslope. Thus the lag time of the hydrograph 
response for the saturated area concentrated closer to the outlet for a coarser DEM resolution is much shorter then that for the finer resolution DEM where the saturated area extends further upslope. This is why the same effective parametric value of $n$ that fit the simulated hydrograph at $50 \mathrm{~m}$ DEM resolution in Figure 4 (a) could not produce an appropriate delay in translation time for $1000 \mathrm{~m}$ DEM as shown in Figure 4 (b).

At this point an obvious question that can be raised is what if the whole catchment is actually contributing the runoff. If this is the case then every point in a catchment is producing the runoff. In this case too, the response time of the flood wave in routing is much delayed when using fine resolution DEM instead of coarse resolution DEM. For $50 \mathrm{~m}$ DEM resolution, the surface runoff has to be routed through out the finer drainage network before accumulating the surface runoff at the points where the contributing area is equal or more than $1 \mathrm{~km}^{2}$. But on the other hand, this portion of the routing delay if we take $1000 \mathrm{~m}$ DEM resolution, does not take part as the water is instantly accumulated in a 1 $\mathrm{km}^{2}$ of a grid. Thus using $1000 \mathrm{~m}$ DEM resolution the routed hydrograph response is faster as the routed distance is shorter. From the chaos theory ${ }^{9)}$ this problem of routed length becomes clearer. If the DEM is infinitely small the routing length is infinitely large and hence the time of concentration.

In Muskingum-Cunge routing method $K$ parameter defined by Equation (7) is the flood travel time over a reach with length $\Delta x$, and it has the connotation of storage delay time, travel time, translation time, or lag time ${ }^{10)}$. This research proposes a method to scale this $K$ parameter as defined by Equation (19) which increases the underestimation of the travel time when a coarse DEM is used. Thus, with the application of the scale invariant Muskingum-Cunge routing method, similar simulated hydrograph calibrated at $50 \mathrm{~m}$ DEM resolution, in Figure 4 (a), is also obtained from $1000 \mathrm{~m}$ DEM resolution, in Figure 4 (c). The Nash efficiency increased from $92 \%$ in Figure 4 (b) to $94 \%$ in Figure 4 (c). Figure 4 is the scale effect seen at the outlet of the catchment. It is more important to analyze this discrepancy in the distributed routing components within the catchment. This discrepancy in flow variable at different scales is significant in displayed Figure 1 and has been solved successfully through the downscaling methods developed by this research as displayed in Figures 2 and 3. 1000m resolution distributed radar rainfall data is used for all the simulations in this research.

\section{CONCLUSION}

Basin hydrological response in relations with the geomorphological parameters is influenced by DEM resolution. In this research the method to downscale the geomorphometric parameters is successfully applied to develop the downscaling methods of the flow variables and a scale invariant model in surface flow hydrology. These downscaling methods of the flow variables, whose propagation characteristics are of interest, are coupled in the Muskingum-Cunge routing method and developed a Scale Invariant Muskingum-Cunge routing model. This has enhanced the consistency across the scales of the DEM resolution dependent parametric value like Manning's roughness coefficient $n$. It is hoped that the findings of this research seek its applicability as a tool to a wider range of boundary as per the scale problems in hydrological processes and solution approach is concerned.

\section{REFERENCES}

1) Pradhan, N. R., Tachikawa, Y., and Takara, K., A scale invariance model for spatial downscaling of topographic index in TOPMODEL, Annual Journal of Hydraulic Engineering, JSCE, vol. 48, 109-114, 2004.

2) Beven, K. J. and Kirkby, M. J., A physically based, variable contributing area model of basin hydrology, Hydrol. Sci Bull. 24, 43-69, 1979.

3) Pradhan, N. R., Tachikawa, Y., and Takara, K., A downscaling method of topographic index distribution for matching the scales of model application and parameter identification, Hydrological Processes (accepted).

4) Cunge, J. A., On the subject of a flood propagation computation method (Muskingum Method), Journel of Hydraulic Research. 7, 205-230, 1969.

5) Leopold, L. B., Maddock, T., The hydraulic geometry of stream channels and some physiographic implications. U.S. Geol. Surv. Prof. Paper, 252, 1953.

6) Pradhan, N. R., Development of a topographic disaggregation method for transferring hydrological models across scales and regions, Ph. D. Thesis, Kyoto University, 2005.

7) Strahler, A. N., Quantitative geomorphology of drainage basins and channel networks, Handbook of Applied Hydrology, Chow VT (ed.). McGraw-Hill: New York, 1964.

8) Cordova, J. R., Rodriguez-Iturbe I. Geomorphoclimatic estimation of extreme flow probabilities. Journal of Hydrology, 65, 159-173, 1983.

9) Mandelbrot, B. B., How long is the coast of Britain? Statistical self-similarity and fractional dimension. Science, 156, 636-638, 1967.

10) Singh, V. P., Kinematic Wave Modeling in Water Resources: Surface-Water Hydrology, Wiley Interscience: New York, 1996. 